\title{
Cardiopulmonary Bypass Complications in a West African Country (Senegal)
}

\author{
Abdel-Kémal Bori Bata ${ }^{1, *}$, Amadou Gabriel Ciss ${ }^{1}$, Momar Sokhna Diop ${ }^{1}$, Papa Salmane Ba ${ }^{1}$, \\ Papa Amath Diagne ${ }^{1}$, Ndeye Fatou Sow ${ }^{1}$, Gaye Magaye ${ }^{1}$, Souleyman Diatta ${ }^{1}$, Mohamed Leye ${ }^{2}$, \\ Etienne Birame Sene ${ }^{3}$, Diene Samba ${ }^{1}$, Papa Adama Dieng ${ }^{1}$, Assane Ndiaye ${ }^{1}$, Mouhamadou Ndiaye ${ }^{1}$ \\ ${ }^{1}$ Department of Thoracic and Cardiovascular Surgery Fann University Hospital, Dakar, Senegal \\ ${ }^{2}$ Department of Cardiology Fann University Hospital, Dakar, Senegal \\ ${ }^{3}$ Department of Anesthesiology Fann University Hospital, Dakar, Senegal
}

\section{Email address:}

bbak@live.fr (Abdel-Kémal B. B.), cissgaby@yahoo.fr (A. G. Ciss.), momarsokhna08@yahoo.fr (M. S. Diop), mansalb@yahoo.fr (P. S. Ba), diagnepapaamath@gmail.com (P. A. Diagne), zenefes@gmail.com (N. F. Sow), mgaye99@yahoo.fr (G. Magaye), soul.diatta@yahoo.fr (S. Diatta), leyemohamed@gmail.com (M. Leye), biramsene@hotmail.com (E. B. Sene), scdiene@gmail.com (D. Samba), padiengsala@yahoo.fr (P. A. Dieng), lazanat@yahoo.fr (A. Ndiaye), mondiaye@orange.sn (M. Ndiaye)

${ }^{*}$ Corresponding author

\section{To cite this article:}

Abdel-Kémal Bori Bata, Amadou Gabriel Ciss, Momar Sokhna Diop, Papa Salmane Ba, Papa Amath Diagne, Ndeye Fatou Sow, Gaye Magaye, Souleyman Diatta, Mohamed Leye, Etienne Birame Sene, Diene Samba, Papa Adama Dieng, Assane Ndiaye, Mouhamadou Ndiaye. Cardiopulmonary Bypass Complications in a West African Country (Senegal). International Journal of Cardiovascular and Thoracic Surgery. Vol. 4, No. 1, 2018, pp. 5-9. doi: 10.11648/j.ijcts.20180401.12

Received: November 30, 2017; Accepted: December 20, 2017; Published: January 9, 2018

\begin{abstract}
Although cardiopulmonary bypass (CPB) has simplified open heart surgery, it causes adverse effects on the body's systems. This study aims to report the complications related to CPB at the Cardiac Surgery Center of the University Hospital in Dakar (Senegal). This is a retrospective analytical and descriptive study covering a 24 months period (from January 2015 to December 2016). All adult and children patients who underwent open heart surgery using CPB machines were included in this study. 193 patients were eligible during this study's period. Patients' mean age was $23 \pm 15$ years (range, 2-65), and 52\% were female patients. Two complications were observed during CPB. One case of hemolysis and one case of an impossible weaning from CPB. Post-CPB complications were allocated as follows: hematological complications (88.5\%) followed by cardiovascular (56\%), pleuropulmonary $(22.4 \%)$, septicemia (4\%), renal (3\%), systemic inflammatory response syndrome (SIRS) $(2 \%)$ and neurologic $(1 \%)$ complications. The overall hospital mortality was $5 \%$. One (1) patient died intra operatively and nine (9) patients in the intensive care unit. The morbidity and mortality related to CPB in our cardiac surgery center is superimposed to those of the literature.
\end{abstract}

Keywords: Cardiopulmonary Bypass, Complications, Open Heart Surgery

\section{Introduction}

Cardiopulmonary bypass (CPB) is a blood circulation external derivation technique during which the cardiac and pulmonary functions are temporarily assured by a mechanical system connected to the vascular system of the patient. The CPB is the machine that allows surgeons to operate on a nonmoving, bloodless heart. The first successful series of open-heart surgery utilizing CPB machines occurred in 1953 by John Gibbon [1]. Nowadays, and throughout the world, the use of the CPB machine during cardiac surgery has become a widely employed practice. However, open heart surgery (OHS) has only recently been introduced in Africa; in Sub-Saharan Africa, it started in the 70's. The first OHS in the West African sub region was performed in Nigeria in 1974; in Senegal, it was performed 1996. [2, 3]

Although CPB has simplified open heart surgery, it also causes adverse effects on a body systems, including 
complications of the inflammatory system, heart, lungs, kidneys, and brain.

The aim of this study is to report the complications related to CPB at the Cardiac Surgery Center of the University Hospital of Fann in Dakar (Senegal).

\section{Method}

This is a retrospective analytical and descriptive study covering a 24 months period (from January 2015 to December 2016).

\subsection{Inclusion et Exclusion Criteria}

All adult and children patients who underwent OHS using CPB machine were included in this study.

One hundred ninety-three (193) patients were eligible during this period. The clinical characteristics of all patients are listed in table 1 . The patients had no preoperative biological abnormality. Preoperative diagnoses are listed in table 2.

Table 1. Preoperative features.

\begin{tabular}{|c|c|}
\hline Characteristics & Values \\
\hline Age Mean \pm SD years [range] & $23 \pm 15[2-65]$ \\
\hline $\mathrm{BMI}$ Mean $\pm \mathrm{SD}$ [range] & $18 \pm 4.4[9-35]$ \\
\hline Sex Female & $52 \%$ \\
\hline Previous cardiac surgery & $4 \%$ \\
\hline \multicolumn{2}{|l|}{ Comorbidities (frequency) } \\
\hline Ischemic stroke & 4 \\
\hline Down's Syndrome & 2 \\
\hline High blood pressure & 1 \\
\hline \multicolumn{2}{|l|}{ New York Heart Association class } \\
\hline Absence or NYHA I & $1.5 \%$ \\
\hline NYHA II & $71 \%$ \\
\hline NYHA III & $27.5 \%$ \\
\hline \multicolumn{2}{|l|}{ Electrocardiogram } \\
\hline Normal sinus rhythm & $81 \%$ \\
\hline $\mathrm{AAF}$ & $16 \%$ \\
\hline Other (atrial flutter, atrial fibrillation) & $3 \%$ \\
\hline \multicolumn{2}{|l|}{ Chest X-ray } \\
\hline Indirect sign of $\mathrm{PAH}$ & $60 \%$ \\
\hline Hemoglobin Mean \pm SD [range] & $13.4 \pm 2.5 \mathrm{~g} / \mathrm{dL}[7-25]$ \\
\hline Hemoglobin $<12 \mathrm{~g} / \mathrm{dL}$ & $22 \%$ \\
\hline Hematocrit Mean \pm SD [range] & $39.3 \pm 8.3 \%[20-80]$ \\
\hline \multicolumn{2}{|l|}{ Transthoracic echocardiography } \\
\hline PAH & $58 \%$ \\
\hline Left atrial enlargement & $60 \%$ \\
\hline sPAP & $63 \pm 19 \mathrm{~mm}[38-123]$ \\
\hline LVEF & $65 \% \pm 9 \mathrm{~mm}[40-87]$ \\
\hline Tricuspid regurgitation & $49 \%$ \\
\hline Grade I & $18 \%$ \\
\hline Grade II & $49 \%$ \\
\hline Grade III & $18 \%$ \\
\hline Grade IV & $15 \%$ \\
\hline
\end{tabular}

BMI: body mass index; SD: standard deviations; PAP: systolic pulmonary artery pressure.

PAH: pulmonary arterial hypertension; AAF: Arrhythmia Atrial fibrillation.

Table 2. Preoperative diagnoses.

\begin{tabular}{lll}
\hline Diagnoses & Frequency & Percentage \\
\hline Mitral regurgitation & 44 & 22.8 \\
Mixed mitral desease & 29 & 15 \\
Mitral stenosis & 34 & 17.6 \\
\hline
\end{tabular}

\begin{tabular}{lll}
\hline Diagnoses & Frequency & Percentage \\
\hline Aortic regurgitation & 7 & 3.6 \\
Mixed aortic desease & 4 & 2.1 \\
Aortic stenosis & 2 & 1 \\
Tetralogy of Fallot & 23 & 11.9 \\
Atrial septal defect & 19 & 9.8 \\
Ventricular septal defect & 13 & 6.7 \\
Subaortic diaphragm & 12 & 6.1 \\
Atrioventricular Canal defect & 3 & 1.5 \\
Pulmonary infundibular stenosis & 1 & 0.5 \\
Left Atrial Myxoma & 1 & 0.5 \\
Pentalogy of Fallot & 1 & 0.5 \\
\hline
\end{tabular}

\subsection{Statistical Methods}

All analyses were conducted with IBM $^{\circledR}$ SPSS $^{\circledR}$ Statistics Version 22 under a bilateral hypothesis with a type-I error set at $5 \%$. For descriptive analyses, the categorical variables were expressed as number and percentage; the quantitative variables were expressed as mean \pm standard deviation (SD) in case of Gaussian distribution, or by quartiles and range otherwise.

\subsection{Surgery}

The CPB had been established using ascending aorta and bicaval cannulations in $90 \%$ of cases. In other cases, the aortic cannulation was associated with a single cannulation of the right atrium with a "two-stage" cavoatrial cannula. Heparincoated circuits were used in all cases. The anticoagulation was performed with heparin. The priming volume contained heparin in $84 \%$ of cases with a mean of $8092 \pm 3740 \mathrm{IU}$ (range, 1000-15000). By adding the dose of heparin in the priming and that administered parenterally; the mean total dose of heparin was $26167 \pm 9720 \mathrm{IU}$ (range, 6000-45000). No cases of heparin resistance have been reported. The mean ACT (Activated clotting time) before starting CPB was $506 \pm 167$ seconds (sec) (range, 320-1443). During CPB, the mean of minimum ACT was $436 \pm 134 \mathrm{sec}$, the mean of maximum ACT was $561 \pm 179 \mathrm{sec}$. No cardiotomy filter was replaced. The surgical procedures are listed in table 3. Operative data of the patients are listed in table 4. Cross clamp times was superior to 120 minutes (min) in 7 cases. The resumption of cardiac activity had occurred in normal sinus rhythm (74.5\%), ventricular fibrillation (14.5\%), atrioventricular block (AVB) $(8.3 \%)$. Intra operative hemodynamic status was stable under vasoactive drug in $31 \%$ of cases.

Table 3. Surgical procedures.

\begin{tabular}{ll}
\hline Surgical procedures & Percentage \\
\hline Mitral valve replacement & 26 \\
Mitral valve replacement + Tricuspid valve repair & 17 \\
Aortic valve replacement & 8 \\
Mitral valve replacement + Aortic valve replacement & 6 \\
Mitral valve repair & 5 \\
Tetralogy of Fallot correction & 12 \\
Correction of atrial septal defect & 10 \\
Correction of ventricular septal defect & 7 \\
Resection of subaortic diaphragm & 6 \\
Correction Atrioventricular septal defect & 1.5 \\
Pentalogy of Fallot correction & 0.5 \\
Correction of pulmonary infundibular stenosis & 0.5 \\
Resection of left atrial myxoma & 0.5 \\
\hline
\end{tabular}


Table 4. Operative data

\begin{tabular}{|c|c|c|}
\hline Operative characteristics & & Values \\
\hline Aortic cannula & & $18 \pm 3 \mathrm{~F}[10-22]$ \\
\hline Inferior vena cava cannula & Size: Mean \pm SD [range] & $27 \pm 6 \mathrm{~F}[14-34]$ \\
\hline Superior vena cava cannula & & $26 \pm 6$ F [12-40] \\
\hline \multicolumn{3}{|l|}{ Priming } \\
\hline Crystalloid & & $93 \%$ \\
\hline Blood & & $7 \%$ \\
\hline \multicolumn{3}{|l|}{ Cardioplegia } \\
\hline Crystalloid & & $69.4 \%$ \\
\hline Cold blood & & $28.5 \%$ \\
\hline Warm blood & & $2 \%$ \\
\hline \multicolumn{3}{|l|}{ Central temperature } \\
\hline Mild hypothermia & & $32 \%$ \\
\hline Moderate hypothermia & & $32 \%$ \\
\hline Normothermia & & $36 \%$ \\
\hline CPB Time & & $90 \pm 34 \min [26-343]$ \\
\hline Cross clamp time & Mean \pm SD [range] & $66.3 \pm 28.5 \min [18-214]$ \\
\hline Minimum Hematocrit during CPB & & $28.4 \pm 6 \%[14-46]$ \\
\hline Hemofiltration (the usage rate of) & & $63 \%$ \\
\hline UF conventionnelle & & $94 \%$ \\
\hline UF + MUF & & $5 \%$ \\
\hline MUF & & $1 \%$ \\
\hline Flow of CPB & & $3.1 \pm 0.8 \mathrm{1} / \mathrm{min} / \mathrm{m}^{2}[0.9-5.5]$ \\
\hline Mean arterial pressure & Mean \pm SD [range] & $60.4 \pm 9.3 \mathrm{mmHg}[40-80]$ \\
\hline Diuresis during CPB & & $286.3 \pm 290 \mathrm{ml}[10-1800]$ \\
\hline
\end{tabular}

F: French; min: minutes; UF: ultrafiltration; MUF: Modified ultrafiltration.

\section{Results}

Two complications were observed during $\mathrm{CPB}$. One case of hemolysis due to an accident of blood transfusion via the CPB circuit because an inappropriate blood type had been transfused. The second complication was an impossible weaning from $\mathrm{CPB}$. The patient died intra operatively after a voluntary stoppage of $\mathrm{CPB}$ assistance. After a $\mathrm{CPB}$ time of
343 min, cross clamp time of 214 min and CPB assistance of $120 \mathrm{~min}$. It was a 19-year-old patient operated for a mitral and aortic valve replacement. We did not have an extracorporeal life support device.

Post-CPB complications are listed in table 5. No case of allergic reactions to protamine sulfate and heparin-induced thrombocytopenia had been reported.

Table 5. Post-cardiopulmonary bypass complications.

\begin{tabular}{ll}
\hline Complications & Values \\
\hline Hematological & $88.5 \%$ \\
Anemia (hemoglobin $<10 \mathrm{~g} / \mathrm{dL})$ & $43.5 \%$ \\
Hemoglobin: Mean \pm SD [range] & $8.5 \pm 1.1 \mathrm{~g} / \mathrm{dL}[5-9,9]$ \\
Hyperleukocytosis $\left(>10000 \mathrm{~mm}^{3}\right)$ & $56 \%$ \\
Leukocytes: Mean \pm SD [range] & $17123 \pm 4854 \mathrm{cells} / \mathrm{mm}^{3}[11100-30400]$ \\
Low level of prothrombin ratio & $62 \%$ \\
Prothrombin Ratio: Mean \pm SD [range] & $48 \pm 9 \%[14-63]$ \\
Thrombocytopenia & $25 \%$ \\
Platelets: Mean \pm SD [range] & $102277 \pm 34355 \mathrm{cells}^{-\mathrm{mm}^{3}}[12000-14800]$ \\
Hemolysis & $0.5 \%$ \\
Surgical bleeding & $1 \%$ \\
Biological bleeding & $11 \%$ \\
Reoperation & $4 \%$ \\
Reoperation for biological bleeding & $2 \%$ \\
Reoperation for Surgical bleeding & $1 \%$ \\
Reoperation for accidental removal of temporary electrode epicardials pacing & $0.5 \%$ \\
Cardiovascular & $56 \%$ \\
Right Ventricular Dysfunction & $52 \%$ \\
TAPSE: Mean \pm SD [range] & $9.5 \pm 2.5 \mathrm{~mm}[4-14]$ \\
Left Ventricular Dysfunction & $15.5 \%$ \\
LVEF: Mean \pm SD [range] & $40 \pm 5.6 \%[25-45]$ \\
PAH & $12.4 \%$ \\
sPAP: Mean \pm SD [range] & $55 \pm 18.4 \mathrm{mmhg}[38-104]$ \\
Others: (AVB, arrhythmia, AF...) & $8.5 \%$ \\
Pleuropulmonary & $22.4 \%$ \\
\hline
\end{tabular}




\begin{tabular}{ll}
\hline Complications & Values \\
\hline Bronchopneumonia & $16 \%$ \\
Pleural effusion & $5 \%$ \\
Pneumothorax & $3 \%$ \\
Atelectasis and ARDS & $1 \%$ \\
Hepatosplanchnic & $18 \%$ \\
Biological hepatic cytolysis (often asymptomatic) & $16 \%$ \\
ASAT: Mean \pm SD [range] & $114 \pm 50 \mathrm{mmol} / \mathrm{L}[58-262]$. \\
Functional Intestinal Obstruction & $2.6 \%$ \\
Diarrhea and dyspepsia & $1 \%$ \\
Renal & $3 \%$ \\
Acute kidney injury & $3 \%$ \\
Neurologic & $1 \%$ \\
Ischemic stroke & $0.5 \%$ \\
Anoxic encephalopathy & $0.5 \%$ \\
Septicemia & $4 \%$ \\
SIRS & $2 \%$ \\
\hline
\end{tabular}

AVB: atrioventricular block; ARDS: (acute respiratory distress syndrome); PAH: pulmonary arterial hypertension.

LVEF: Left ventricular ejection fraction; sPAP: systolic pulmonary artery pressure; AF: Atrial fibrillation.

TAPSE: tricuspid annular plane systolic excursion; ASAT: aspartate aminotransferase.

SIRS: systemic inflammatory response syndrome.

The overall hospital mortality was $5 \%$ (10 cases). One (1) patient died intra operatively and nine (9) patients in the ICU (intensive care unit). Cause of death was multiple organ failures (4 cases), right ventricular dysfunction associated with pulmonary arterial hypertension (3 cases), septic shock associated with AVB (1 case), bleeding caused by disunity of superior vena cava suture line ( 1 case). The mean length of stay in the ICU was $3.8 \pm 2$ days (range, 2-18).

\section{Discussion}

Complications after use of cardiopulmonary bypass are common. Acute accidents and incidents occurring during CPB are in the order of $0.4-1 \%$ [4]. It was in order of $1 \%$ in our series. Apart from a blood transfusion accident via the $\mathrm{CPB}$ circuit, the second complication was an impossible weaning from $\mathrm{CPB}$. This case required cardiopulmonary support for failure to wean from CPB. However, we did not have an extracorporeal life support device. Predictors of difficult weaning from $\mathrm{CPB}$ are: prolonged aortic cross clamp time $>60$ minutes, prolonged bypass time, poor myocardial preservation during $\mathrm{CPB}$, prebypass Delta $\mathrm{PCO}_{2}>6 \mathrm{mmhg}$, preoperative diastolic dysfunction, $\mathrm{PAH}$ (pulmonary arterial hypertension) [5].

Post-CPB complications were dominated by hematological complications. Postoperative anemia (43.5\%), hyperleukocytosis $(56 \%)$, low level of prothrombin ratio $(62 \%)$ and thrombocytopenia (25\%) were the most prevalent. In the literature, the rate of anemia post-CPB range from 48 to $51 \%$ [6], the mean hemoglobin post-CPB ranges from 9.3 to $11 \mathrm{~g} / \mathrm{dL}$, the ratio of thrombocytopenia ranges from 35 to $65 \%$ [8]. The postoperative anemia increases postoperative morbidity or the length of the hospital stay [7]. Lako et al. reported $90.2 \%$ of the patients with neutrophilic leukocytosis and the maximal level of the leukocytes was $34.170 \mathrm{~mm}^{3}$ [7].

Cardiovascular complications were dominated by right ventricular dysfunction (RVD) (52\%) followed by left ventricular dysfunction (LVD) (15.5\%) and PAH (12.4\%).
RVD are traditionally described after OHS and evaluated by TAPSE. In the literature, the post-CPB TAPSE ranges from 11 to $18 \mathrm{~mm}$ and is correlated with CPB time [9, 10]. LVD after CPB is well known; the LVEF post-CPB ranges from 38 to $59 \%$ [10]. However, LVD is transitional with a recovery within 48 hours. PAH are predictors of difficult weaning from $\mathrm{CPB}$, but also have an impact on mortality and RV function $[5,11]$.

In the literature, pleuropulmonary complications range from 8 to $79 \%$ [12]. In our series, these complications were dominated by bronchopneumonia (16\%); they range from 2 to $22 \%$ in the literature. The rate of pleural effusion ranges from 24 to $95 \%$, that of pneumothorax ranges from 0.7 to 5.3, ARDS (acute respiratory distress syndrome) ranges from 0.4 to $2 \%$ [12].

Acute kidney injury post-CPB was in the order of 3\% in our series; it ranges from 2 to $40 \%$ in the literature $[12,13]$. Hemodilution during CPB, anemia and peri operative blood transfusion are factors that contribute to acute kidney injury [14]. Neurologic complications were in the order of $1 \%$ in our series; it ranges from 1 to $2 \%$ in the low-risk patients and 6 to $8 \%$ in the high-risk patients. The rate of SIRS ranges from 10 to $11 \%$ in the literature. [12]

Our rate of hepatosplanchnic complications has been overestimated because of biological hepatic cytolysis that was often asymptomatic. Therefore, by ignoring biological hepatic cytolysis the rate of hepatosplanchnic complications would become $3.6 \%$.

In our series, the mean length of stay in the ICU was 3.8. In the literature, it ranges from 1 to 4 days. Five predictors of prolonged ICU stay were identified: ejection fraction $<30 \%$, $\mathrm{PAH}$, prolonged ventilation ( $\geq 12$ hours), number of blood units transfused, and postoperative acute renal failure. Hospital mortality ranges from 2 to $4.6 \%$ in the literature. [15]

\section{Conclusion}

The morbidity and mortality related to $\mathrm{CPB}$ in our cardiac 
surgery center is superimposed to those of the literature. Post-CPB complications were dominated by hematological complications followed by cardiovascular and pulmonary complications. Anemia was the most prevalent of hematological complications. Cardiovascular complications were dominated by RVD followed by LVD. Pleuropulmonary complications were dominated by bronchopneumonia. Renal complications were represented by acute kidney injury. However, by improving care and monitoring in intensive care unit; we could reduce our morbidity and mortality.

\section{Competing Interests}

The authors declare there is no conflict of interest.

\section{Acknowledgements}

This research received no specific grant from any funding agency in the public, commercial or not-for-profit sectors.

\section{References}

[1] Hessel EA. History of cardiopulmonary bypass. Best Practice \& Research Clinical Anaesthesiology. 2015; 29: 99-111.

[2] Yangni-Angate KH, Meneas C, Diby F, Diomande M, Adoubi A, Tanauh Y. Cardiac surgery in Africa: a thirty-five-year experience on open heart surgery in Cote d'Ivoire. Cardiovasc Diagn Ther. 2016; 6 (1): 44-63.

[3] Nwiloh JO, Oludara MA, Adebola PA, Edaigbini, SA, Danbauchi S, Sowunmi AC. Experience with prosthetic valve replacement in indigents with rheumatic heart disease in Nigeria: 10-Year Follow-Up. World Journal of Cardiovascular Surgery. 2015; 5 (08): 75.

[4] Mejak BL, Stammers A, Rauch E, Vang S, Viessman T. A retrospective study on perfusion incidents and safety devices. Perfusion 2000; 15 (1): 51-61.

[5] Kim H. Weaning from cardiopulmonary bypass. Korean $\mathbf{J}$ Anesthesiol. 2013; 64 (6): 487-8.
[6] Piednoira P, Lasockia S, Philipa I, Driss F, Boutronc I, Beaumont $\mathrm{C}$, et al. Incidence and impact of anemiaand iron deficiencyin cardiac surgery. Anaesthesia Critical Care \& Pain Medicine. 2008; 27S: 63-6.

[7] Lako S, Dedej T, Nurka T, Ostreni V, Demiraj A, Xhaxho R, et al. Hematological Changes in Patients Undergoing Coronary Artery Bypass Surgery: a Prospective Study. Med Arch. 2015; 69 (3): 181-6.

[8] Rezende E, Morais G, Silva Junior JM, Oliveira AM, Souza JM, Toledo DO, et al. Thrombocytopenia in cardiac surgery: diagnostic and prognostic importance. Rev Bras Cir Cardiovasc. 2011; 26 (1): 47-53.

[9] Denault AY, Couture P, Beaulieu Y, Haddad F, Deschamps A, Nozza A, et al. Right Ventricular Depression After Cardiopulmonary Bypass for Valvular Surgery. J Cardiothorac Vasc Anesth. 2015; 29 (4): 83644.

[10] Maffessanti F, Gripari P, Tamborini G, Muratori M, Fusini L, Alamanni F, et al. Evaluation of Right Ventricular Systolic Function after Mitral Valve Repair: A Two-Dimensional Doppler, Speckle-Tracking, and Three-Dimensional Echocardiographic Study. J Am Soc. Echocardiogr. 2012; 25 (7): 701-8.

[11] Estrada VHN, Franco DLM, Moreno AAV, Gambasica JAR, Nunez CCC. Postoperative Right Ventricular Failure in Cardiac Surgery. Cardiology Research. 2016; 7 (6): 185-95.

[12] Nearman H, Klick JC, Eisenberg P, Pesa N. Perioperative complications of cardiac surgery and postoperative care. Crit Care Clin. 2014; 30 (3): 527-55.

[13] Ball L, Costantino F, Pelosi P. Postoperative complications of patients undergoing cardiac surgery. Current opinion in critical care. 2016 ; 22 (4): 386-92.

[14] Xue FS, Li RP, Sun C. Association Between Acute Kidney Injury and Hemodilution During Cardiopulmonary Bypass. Ann Thorac Surg. 2015; 100: 1966-77.

[15] Meziane M, Koundi A, Meskine A, Bensghir M, Hatim A, Ahtil R, et al. Predictors of prolonged ICU stay following elective adult cardiac surgery: Monocentric retrospective study on 5 and half years. Annales de Cardiologie et d'Angéiologie. 2017; 66: 66-73. 